\title{
Mother's Developmental Expectations From Preschool Education For Their Five-Year-Old Children
}

\author{
Ayşegül ULUTAŞ AVCU ${ }^{1}$
}

\section{Summary}

\section{PURPOSE}

The purpose of this study was to determine the mother's developmental expectations from preschool education for their five-year-old children. The questions "Do expectations of the mothers from preschool education regarding development of their five year-old children differ in terms of family type, educational background, and number of children of mothers?" are sub-goals of the study.

\section{METHOD}

In this study, relational screening model was used in order to examine expectations of the mothers from preschool education regarding development of their five year-old children. The population of the study consisted of 198 mothers of five year-old children receiving education kindergartens affiliated with Malatya Provincial Directorate for National Education. Since all mothers were reached in the study, sample selection was not performed. A questionnaire developed by the researcher was used as data collection tool. The questionnaire consisted of two sections as personal information form and expectations related to development of the children. SPSS 22 packaged software was used to analyze the data. Conformity of quantitative data to normal distribution was examined by using Shapiro-Wilk test and graphical evaluations. Statistical analysis methods to be used following normality tests were determined. Independent samples $t$ test and one-way analysis of variance (One-Way Anova) were used for analysis of the study data. Significance was evaluated at the level of 0.05 .

\section{FINDINGS}

Most of the mothers included in the study had nuclear family type, bachelor's degree, and two children. The expectations of the mothers from preschool education regarding development of their five year-old children showed a significant difference in terms of family type $(\mathrm{p}<0.05)$, did not show a significant difference in terms of educational background of the mother $(\mathrm{p}>0.05)$, and showed a significant difference in terms of the number of children $(\mathrm{p}<0.05)$. As a result of the study, it was determined that expectations of the mothers with nuclear family type and on only child were higher than the other mothers. While the variables of family type and number of children affected the mothers' expectations from preschool education regarding development of their five year-old children, the variable of educational level did not affect their expectations.

\footnotetext{
${ }^{1}$ Assist. Prof., İnönü University, Faculty of Health Sciences, aysegul.ulutas@inonu.edu.tr
} 